\title{
Resuscitative EChocardiography for the Evaluation and management of Shock: The RECES protocol
}

\author{
Jarrod M. Mosier ${ }^{1,2}$ \\ Lori Stolz ${ }^{1}$ \\ John Bloom ${ }^{2}$ \\ Josh Malo ${ }^{2}$ \\ Linda Snyder ${ }^{2}$ \\ Albert Fiorello ${ }^{1}$ \\ Srikar Adhikari ${ }^{1}$ \\ ${ }^{1}$ Department of Emergency Medicine, University of Arizona, Tucson, AZ \\ ${ }^{2}$ Department of Medicine, Section of Pulmonary, Critical Care, Allergy and Sleep, \\ University of Arizona, Tucson, AZ
}

\begin{abstract}
Purpose: Ultrasound use by emergency medicine and critical care physicians in the evaluation of the critically ill patient has increased in recent years. Several protocols exist to aid in diagnosing the etiology of shock and identifying rapidly reversible conditions in the undifferentiated hypotension patient. Currently, no protocol provides hemodynamic data or is designed to guide ongoing resuscitation of the critically ill patient with hypotension.
\end{abstract}

Methods: An evidence-based protocol was developed based on the components of echocardiography that have been supported in the literature for bedside evaluation of the critically ill patient.

Results: The RECES protocol provides diagnostic and hemodynamic information regarding volume responsiveness, presence of pericardial effusion with tamponade physiology (right ventricular diastolic collapse), systolic failure (poor contractility, decreased stroke volume and cardiac output), diastolic dysfunction (mitral valve inflow velocities and tissue Doppler), Right ventricular systolic failure, acute valvular rupture, obvious wall motion abnormalities, and signs of pressure or volume overload (septal flattening on parasternal short axis).

Conclusion: The RECES protocol is a proposed instrument for rapidly and repeatedly assessing the etiology and initial hemodynamic parameters of the patient in shock. Additionally, repeated exams will allow monitoring interventions and guide ongoing resuscitation.

\section{Introduction}

Ultrasound has become indispensible for emergency medicine physicians and intensivists in the evaluation and management of patients in shock. Bedside 
ultrasound is no longer used solely for central line placement and the diagnosis of intra-abdominal free fluid. The emergency bedside applications being used with frequency span nearly every body system. The body of literature substantiating the ability of clinicians to accurately perform and interpret point-ofcare ultrasound studies is robust and growing.

For patients in shock, several goal-directed ultrasound protocols have been described in the literature. Each of these is aimed at finding rapidly reversible etiologies of shock in the undifferentiated hypotensive patient (i.e. tamponade, pneumothorax, intra-abdominal hemorrhage) (1-6). Though similar in their aim, they each differ in respect to the pathology sought, views obtained and the scope of the exam. Of these protocols, systematic study has been undertaken in only two. Jones et al. (2) have demonstrated that goal-directed ultrasound early in the presentation of patients with shock can improve the accuracy of the treating physician's diagnosis within 15 minutes of patient arrival from $50 \%$ accuracy at baseline to $80 \%$ accuracy with the use of ultrasound. Manno et al. (6) found a bedside ultrasound protocol in all admitted ICU patients changed the admitting diagnosis in $25.6 \%$ of patients, prompted further testing in $18.4 \%$ of patients and altered medical therapy in $17.6 \%$ of patients.

Bedside cardiac ultrasound in particular has been adopted as a key component of the emergent evaluation of critically ill patients $(7,8)$. Cardiac ultrasound in the hands of non-cardiologist and non-radiologist clinicians has been shown to be accurate and reliable in diagnosing a wide array of pathologies. One paper has described a limited echocardiography protocol for use in trauma intensive care patients with the aim of evaluating for pericardial effusion, ventricular function and volume status (9). All whole-body sonography protocols that have been described for the evaluation of shock incorporate a limited cardiac exam. Within both studies described above, the cardiac portion yielded positive findings most frequently $(2,6)$. However, despite these advances in clinical practice, to our knowledge no standardized, goal-directed bedside echocardiography protocol currently exists to guide the ongoing resuscitation of patients in shock.

This novel goal-directed echocardiography protocol was developed to provide immediate diagnostic information as to the etiology of shock similar to other protocols as well as provide hemodynamic information useful to guiding and assessing therapy during ongoing resuscitation. The protocol is taught to critical care and emergency ultrasound fellows at our institution as well as emergency medicine residents rotating in the ICU. It is designed to go beyond diagnosing the etiology of shock and to guide on-going resuscitation of critically ill patients through their hemodynamic crisis. The initial exam serves as a benchmark to which future exams are compared, and subsequent exams monitor the hemodynamic response to interventions. The intention is that this protocol be used on a recurring and as-needed basis to supplement the standard hemodynamic monitoring in a patient with shock 
This protocol [Table 1] is evidence-based.

Table 1. Evaluation parameters: Goal-directed Assessment.

\begin{tabular}{|c|c|c|c|c|}
\hline View & Question & \multicolumn{2}{|c|}{ Answer } & Measurement \\
\hline \multirow{2}{*}{ Subxyphoid } & \multirow{2}{*}{$\begin{array}{l}\text { Pericardial Effusion } \\
\text { IVC }\end{array}$} & \multicolumn{2}{|l|}{$\begin{array}{l}\text { Present } \\
\text { NotPresent }\end{array}$} & \multirow{2}{*}{$\begin{array}{l}\text { IVC plethoric ( }>2 \mathrm{~cm},<20 \% \text { collapsible) } \\
\text { RV diastolic collapse on PLAX? (m- } \\
\text { mode) }\end{array}$} \\
\hline & & $\begin{array}{l}\text { Small }(<2 \mathrm{~cm}) \\
\text { Large }(>2 \mathrm{~cm})\end{array}$ & $\begin{array}{l}\text { Collapsible }(>20 \%) \\
\text { Non-collapsible } \\
(<20 \%)\end{array}$ & \\
\hline $\begin{array}{l}\text { Parasternal } \\
\text { Long Axis }\end{array}$ & Global Systolic Function & \multicolumn{2}{|c|}{$\begin{array}{l}\text { Depressed } \\
\text { Normal } \\
\text { Hyperdynamic }\end{array}$} & LVOT diameter (cm) \\
\hline $\begin{array}{l}\text { Parasternal } \\
\text { Short Axis }\end{array}$ & Wall Motion & \multicolumn{2}{|c|}{$\begin{array}{l}\text { Globally Normal } \\
\text { Globally Abnormal } \\
\text { Regionally Abnormal }\end{array}$} & $\begin{array}{l}\text { "Kissing Papillary Muscles" } \\
\text { Septum Flat in Systole/Diastole }\end{array}$ \\
\hline \multirow{4}{*}{ Apical 4/5 } & $\begin{array}{l}\text { Right Ventricle } \\
\text { Size } \\
\text { Function }\end{array}$ & \multicolumn{2}{|c|}{$\begin{array}{l}\text { Normal } \\
\text { Dilated ( } \geq \text { L } \vee \text { size) } \\
\text { Tricuspid Regurgitation }\end{array}$} & $\begin{array}{l}\text { TAPSE (mm) } \\
\text { PA Systolic Pressure (+RAP) }\end{array}$ \\
\hline & Valvular Regurgitation & \multicolumn{2}{|l|}{$\begin{array}{l}\text { Yes } \\
\text { No }\end{array}$} & Color Doppler \\
\hline & Diastolic Dysfunction & \multicolumn{2}{|l|}{$\begin{array}{l}\text { Yes } \\
\text { No }\end{array}$} & $\begin{array}{l}\text { E/A (MV inflow velocity) } \\
\text { E/e' (MV inflowie' on tissue Doppler) }\end{array}$ \\
\hline & Volume Responsive & \multicolumn{2}{|l|}{$\begin{array}{l}\text { Yes } \\
\text { No }\end{array}$} & $\begin{array}{l}\text { Stroke Volume/Cardiac Output (LVOT } \\
\text { VTi) }\end{array}$ \\
\hline
\end{tabular}

It incorporates the elements of the bedside cardiac exam that have been proven in the literature to be accurate and useful in the emergency setting. It is not designed to replace standard comprehensive echocardiography but rather to be used in locations or situations where obtaining a complete echocardiogram is not possible or feasible given time of day, availability of formal echo services and clinical condition of the patient. Additionally, the protocol can be repeated after an intervention to assess progress during resuscitation whereas repeated formal echocardiograms are not reasonable. The information obtained at the bedside from this protocol is potentially useful for diagnosing the etiology of shock, and guiding resuscitation of patients with hemodynamic instability. It is not intended to manage the subtleties of chronic cardiovascular disease or valvular disease.

A key element to the use of this protocol is the potential to determine response to therapy to help on-going resuscitation of patients with hemodynamic instability. In a volume-depleted patient, for example, a repeat exam could be performed following each fluid bolus. Traditionally, clinical exam findings of excessive fluid administration can be monitored but occur after the desired intravascular volume status has been surpassed and possible patient harm has been done. A patient in shock who, after several liters of fluid, no longer demonstrates intravascular volume depletion can be assuredly started on vasopressors. Additionally, a patient who continues to demonstrate volume responsiveness with a large stroke volume may be started on vasopressors in the setting of diastolic failure. This phenomenon is also seen as a result in increased arterial elastance which is unlikely to improve from further fluid administration. 
This protocol [Table 1] proceeds with several qualitative questions along with obtaining several quantitative hemodynamic parameters in the process.

Following is a description of each step in the protocol:

\section{Pericardial effusion}

Q: Is there a pericardial effusion present? Yes or No

Q: If there is a pericardial effusion present, is there evidence of tamponade physiology (i.e. right ventricular diastolic collapse and/or plethoric inferior vena cava)? Yes or No

This protocol begins with an evaluation for pericardial effusion. The use of bedside ultrasound to diagnose pericardial effusion was one of the first applications employed by emergency medicine and critical care specialists. Emergency physicians can detect pericardial effusion on bedside ultrasound with a sensitivity of $96 \%$ and a specificity of $98 \%$ (10). Hand-carried ultrasound units have been used in cardiac ICUs to identify pericardial effusion (11). Although the sensitivity and specificity of these handheld units was $75 \%$ and $88 \%$ respectively, for all effusions, all false negatives had less than $20 \mathrm{mls}$ of pericardial fluid on contrast enhanced CT and all false positives were estimated to be trace as well (11). Bedside ultrasound in undifferentiated dyspneic patients found pericardial effusion in $13.6 \%$ of patients, $29 \%$ of which required pericardiocentesis (12). If identified, the clinician can then evaluate for echocardiographic signs of tamponade. The elements of comprehensive echocardiographic evaluation for tamponade that are likely to be obtainable with a bedside machine by a noncardiologist clinician are right ventricular diastolic collapse and inferior vena cava plethora (Figure 1) $(13,14)$. However, as described below, inferior vena cava plethora can be caused by any elevation of right-sided pressures and should be interpreted in the context of the other findings on the exam.

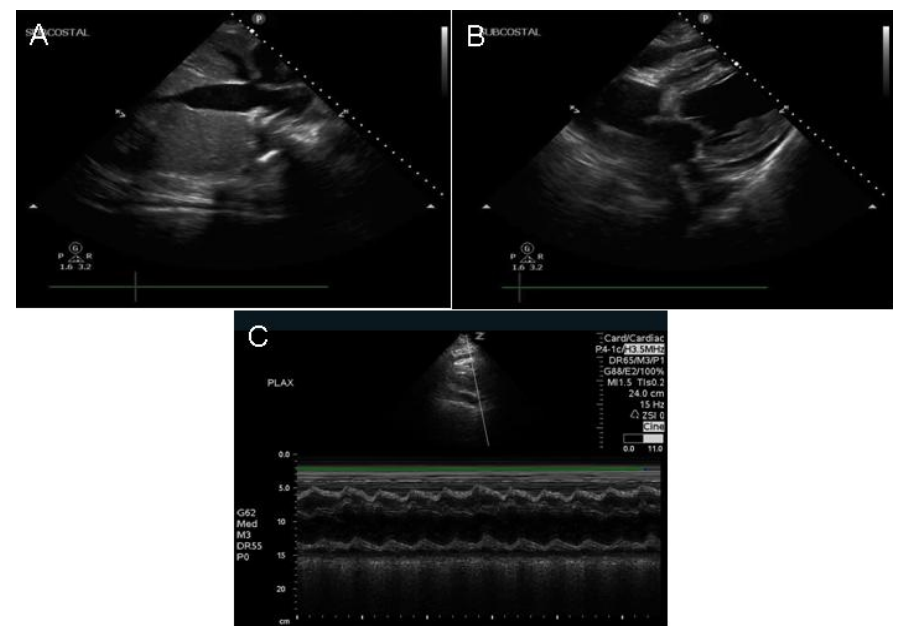

Figure 1. Panel A: Plethoric, non-collapsible IVC suggests elevated right sided pressures or tamponade physiology. Panel B: Presence of pericardial effusion on subxyphoid view is small, but shows diastolic right ventricular collapse. Panel C:

M-mode on parasternal long axis suggests tamponade physiology. 


\section{Global systolic function \\ Q: Is the left ventricular global systolic function decreased, normal, or hyperdynamic? \\ Q: What is the stroke volume and cardiac output?}

In this protocol, left ventricular systolic function is assessed globally and is graded as decreased, normal, or hyperdynamic, rather than quantitatively estimating left ventricular ejection fraction (LVEF). Although LVEF is a numerical representation of left ventricular function, it is difficult to obtain in the acute setting and influenced by critical illness, as well as anatomic and physiologic factors limiting adequate endocardial visualization (15). Additionally, as LVEF is not influenced by hemodynamic parameters (preload, afterload), it is less useful for the acute hemodynamic evaluation of the patient in shock (16). E-point septal separation (EPSS) has been compared to magnetic resonance imaging methods of calculating ejection fraction with good correlation; however that correlation declines in the presence of wall motion abnormalities and valvular disease $(17,18)$. Ahmadpour et al. (19) demonstrated EPSS to be a reliable index of ventricular performance in coronary artery disease patients but only as a predictor of decreased ejection fraction rather than estimating the exact ejection fraction. Secko et al. (20) showed that novice emergency physician obtained EPSS measurements correlated well with visual estimates of EF; however EPSS as a continuous variable did not correlate well with fractional shortening measurements in a study by Weekes et al. (21). These data would suggest that estimating LVEF by either estimating quantitatively or by EPSS is inconsistent and not indicative of the underlying hemodynamic state. Instead of attempting to quantify ejection fraction, this protocol uses visual estimates of LV systolic function obtained in each view, which have been shown to be accurate and easily performed at the bedside (16,22-24).

\section{IVC}

Q: Is the IVC small $(<2 \mathrm{~cm})$ or large $(>2 \mathrm{~cm})$ ?

Q: Is the IVC dynamic ( $>20 \%$ change in diameter with respiration)? Assessing volume responsiveness in hypotensive patients is of paramount importance for restoring intravascular volume without deleteriously volume overloading the patient, which has been shown to worsen outcomes (2528). Traditionally, central venous pressure (CVP) has been used as an endpoint of volume resuscitation (29). CVP as a measure of ventricular preload has been shown to poorly correlate with intravascular volume status and volume responsiveness (30-32). Rather than static CVP measurements, dynamic volume assessments reflected by cardiopulmonary interactions are more accurate and reliable for predicting improved cardiac index with volume infusion (33-40). Bedside ultrasound assessment of dynamic changes in inferior vena cava diameter with either distensibility (IVCd) in the case of a mechanically ventilated patient or collapsibility in a spontaneous breathing is a pre-heart/lung observation of cardiopulmonary interactions and has been shown to be reliable for predicting volume responsiveness $(34,35,39,41,42)$. This protocol uses IVCd as one of 
three assessments of volume responsiveness along with obliteration of the LV cavity on parasternal short axis (papillary level) and left ventricular outflow tract $\mathrm{VTi}$. Since evidence of IVCd measurement in the presence of cirrhosis and alternative ventilator modes such as airway pressure release ventilation (APRV) is lacking, it is not ideal as the sole assessment for volume responsiveness. A plethoric IVC can be seen in both high right-sided pressure (pulmonary embolism, RV infarct) and in tamponade physiology. A plethoric IVC in the absence of pericardial effusion should alert the physician to the presence of high right-sided pressure or RV volume overload. Additionally, determination of adequate intravascular volume status can guide clinicians in initiation or titration of pressor support.

\section{Volume Responsiveness}

Q: Does this patient appear to be volume responsive (i.e. in addition to IVC collapsibility, is there a hyperdynamic LV with cavity obliteration on systole and is there variability in the LVOT VTi)? Yes or No

In addition to IVCd, this protocol uses a global assessment of the left ventricular dynamics and the left ventricular outflow tract velocity time integral (LVOT VTi) respiratory variation as assessments of volume responsiveness (Figure 2).
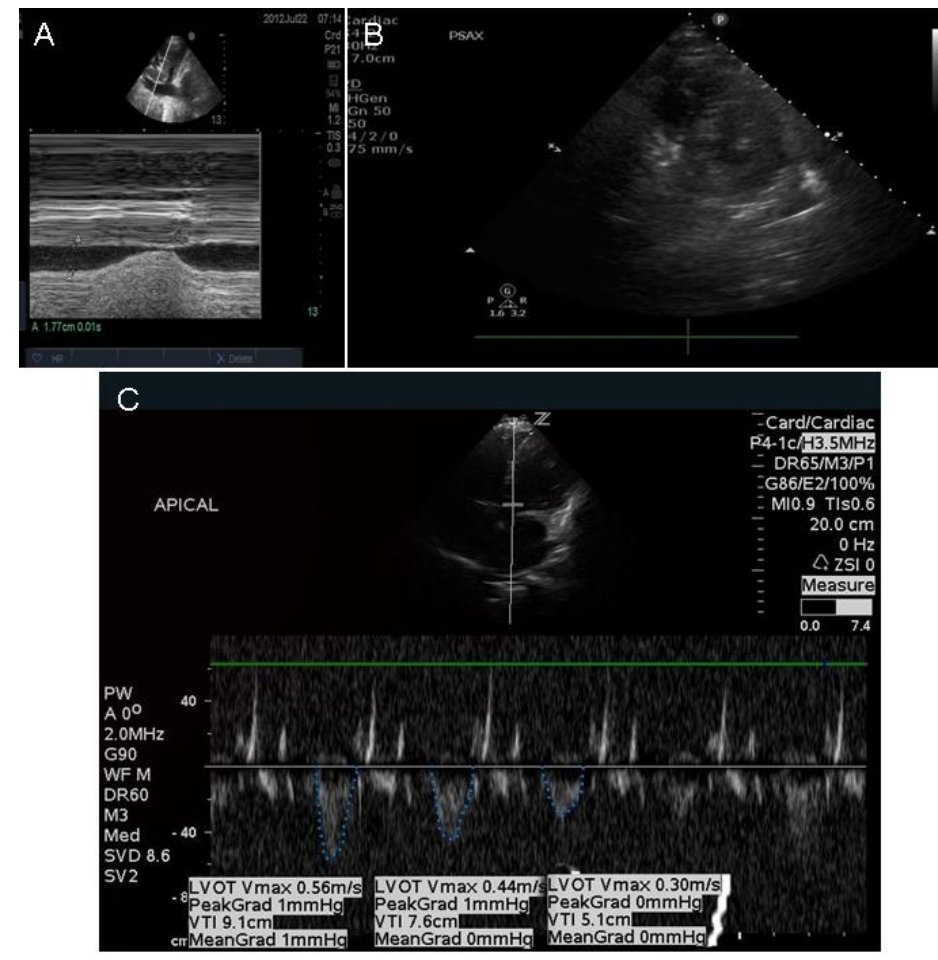

Figure 2. Collapsibility of the IVC (Panel A, top left), hyperdynamic left ventricle with obliteration of the LV cavity on parasternal short axis (Panel B, top right), and variability of the left ventricular outflow tract with inspiration (Panel C, bottom) are indicators of volume responsiveness. 
Left ventricular end diastolic area (LVEDA), if seen as cavitary obliteration or "kissing papillary muscles" on parasternal short axis, has been shown to correlate with the presence of hypovolemia $(43,44)$. LVOT VTi variability has recently been shown to correlate well with non-invasive cardiac output monitors to determine volume responsiveness in hypotensive patients $(45,46)$. The LVOT VTi obtained on an apical 5 chamber can be used with the LVOT diameter obtained in the parasternal long axis view to calculate the stroke volume and cardiac output (Figure 3) $(47,48)$.
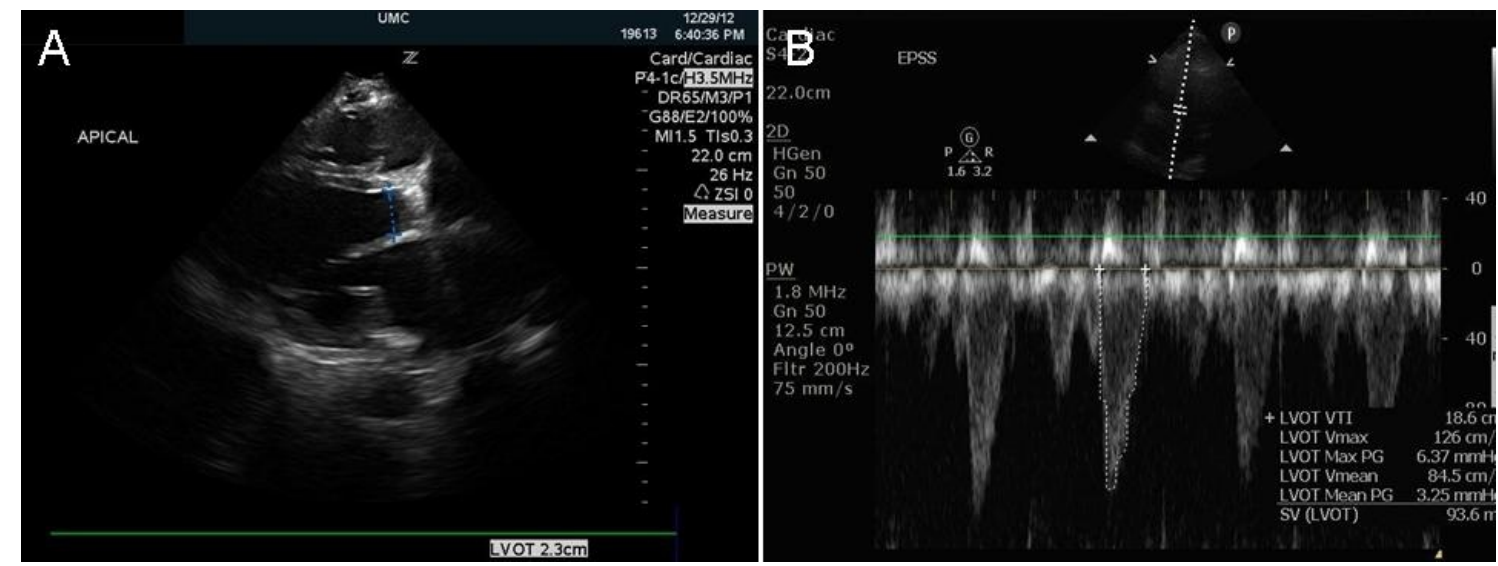

Figure 3. Stroke volume (SV) and cardiac output. The stroke volume is calculated by measuring the diameter of the LVOT on parasternal long axis (Panel A, left) and the LVOT VTi (Panel B, right) [SV=Vti $\left.x \pi(L V O T d / 2)^{2}\right]$. Cardiac output is calculated by multiplying SV by the heart rate.

The LVOT VTi represents a Doppler assessment of cardiopulmonary interactions that translates to stroke volume variation, pulse pressure variation, and systolic pressure variation as seen on an arterial line tracing which has been well correlated with volume responsiveness $(33,36,37,41,42,49)$.

Case 1: A 48-year-old male is admitted to the intensive care unit (ICU) with septic shock secondary to spontaneous bacterial peritonitis. He had received several liters of crystalloid in the ED and remains hypotensive with poor perfusion. RECES protocol was performed on admission to the ICU, which demonstrated the patient was volume responsive; however the stroke volume and cardiac output were elevated suggesting increased vascular elastance rather than intravascular volume depletion. The patient was placed on a vasopressor with improved tissue perfusion and indicators of shock.

\section{Diastolic dysfunction}
Q: Is there diastolic dysfunction? Yes or No
Q: Is there evidence of elevated left atrial pressure? Yes or No

Diastoloic dysfunction plays an increased role as patients age or have chronic hypertension (50). Hemodynamically, this leads to an increased likelihood of 
pulmonary edema with aggressive fluid resuscitation, which has been shown to increase mortality $(25,27,28)$. In this protocol, mitral valve inflow velocities by pulsed wave Doppler (PWD) are used to assess diastolic dysfunction. Mitral E and $A$ waves accurately reflect the pressure gradient between the left atrium and left ventricle and have been shown to be superior to LVEF for estimation of left ventricular function (50). Mitral annulus tissue Doppler (TDI) is used to differentiate between pseudonormal inflow velocity patterns and decreased LV compliance as well as estimate left atrial pressure (50). In grade I diastolic dysfunction, mitral inflow velocities demonstrate an E-A reversal. As left ventricular compliance worsens, the E-A pattern returns to normal; however, the velocities increase, representing the left atrium "pushing" the blood into the left ventricle rather than the ventricle "sucking" blood from the atrium as the cavitary pressure drops below atrial pressure in the normal heart (51). In mechanically ventilated patients diastolic velocities may be altered to some degree by changes in left ventricular compliance, mainly through changes in right ventricular compliance via ventricular interdependence. Additionally, estimated pulmonary artery systolic pressures $>40 \mathrm{mmHg}$ in the absence of known pulmonary hypertension, lung disease, or systolic failure may indicate undiagnosed diastolic dysfunction and caution over-resuscitation with fluids. Emergency physicians can accurately perform this exam at the bedside as shown by Unluer and colleagues (52).

Case 2: An 81-year-old male presents with 3 days of productive cough and fever. The patient is found to be hypotensive and tachycardic with high suspicion for severe sepsis. Electrocardiogram demonstrates LVH with strain, and labs are consistent with a severe sepsis syndrome. RECES protocol is performed on this patient which demonstrates grade III diastolic dysfunction and moderate mitral regurgitation which limited the amount of crystalloid given to avoid worsened pulmonary edema and ARDS.

\section{Wall motion abnormalities Q: Is there any obvious wall motion abnormality (global or regional)? Yes or No}

In a critically ill patient, differentiating shock-induced cardiac dysfunction from cardiogenic shock is difficult. Serial troponins may be helpful but may also be misleading, as in the case of sepsis-induced cardiomyopathy. The consensus statement on the use of focused cardiac ultrasound in the emergent setting recommends comprehensive echocardiography for the diagnosis of wall motion abnormalities (8). To our knowledge, there exists only one paper evaluating the ability of non-cardiologist clinicians to diagnose wall-motion abnormalities. This study showed that a 30-minute training module significantly improved the ability of emergency physicians to identify wall motion abnormalities (53). Though this has not been studied directly, we postulate that a negative exam performed and interpreted by a non-cardiologist clinician, given the skill required in image acquisition and interpretation, does not rule out the presence of wall motion 
abnormalities. However, a clearly positive exam noted by a bedside clinician in a patient with undifferentiated or multi-factorial shock could dramatically improve the quality of their resuscitation. A positive exam will require interpretation in consideration with the clinical picture and ancillary data. For example, sepsisinduced cardiomyopathy may present as global hypokinesia or unmask underlying ischemic cardiac disease especially in the presence of vasopressors or inotropes.

\section{Right ventricle}

Q: Is the right ventricle dilated? Yes or No

Q: Is there tricuspid regurgitation? Yes or No

Q: What is the systolic function of the right ventricle (TAPSE)?

Q: Is there evidence of right ventricular pressure or volume overload

(i.e. septal flattening in systole or diastole)?

Q: What is the estimated pulmonary artery systolic pressure?

The right ventricular systolic movement differs greatly from the left ventricle. As opposed to the rotational component to left ventricular contraction, the right ventricular free wall moves towards the septum, followed by longitudinal contraction bringing the base towards the apex (54). As such, the tricuspid annular plane systolic excursion (TAPSE) using M-mode through lateral tricuspid annulus on an apical 4-chamber view is a reliable measurement of right ventricular systolic function (Figure 4) (54-57).

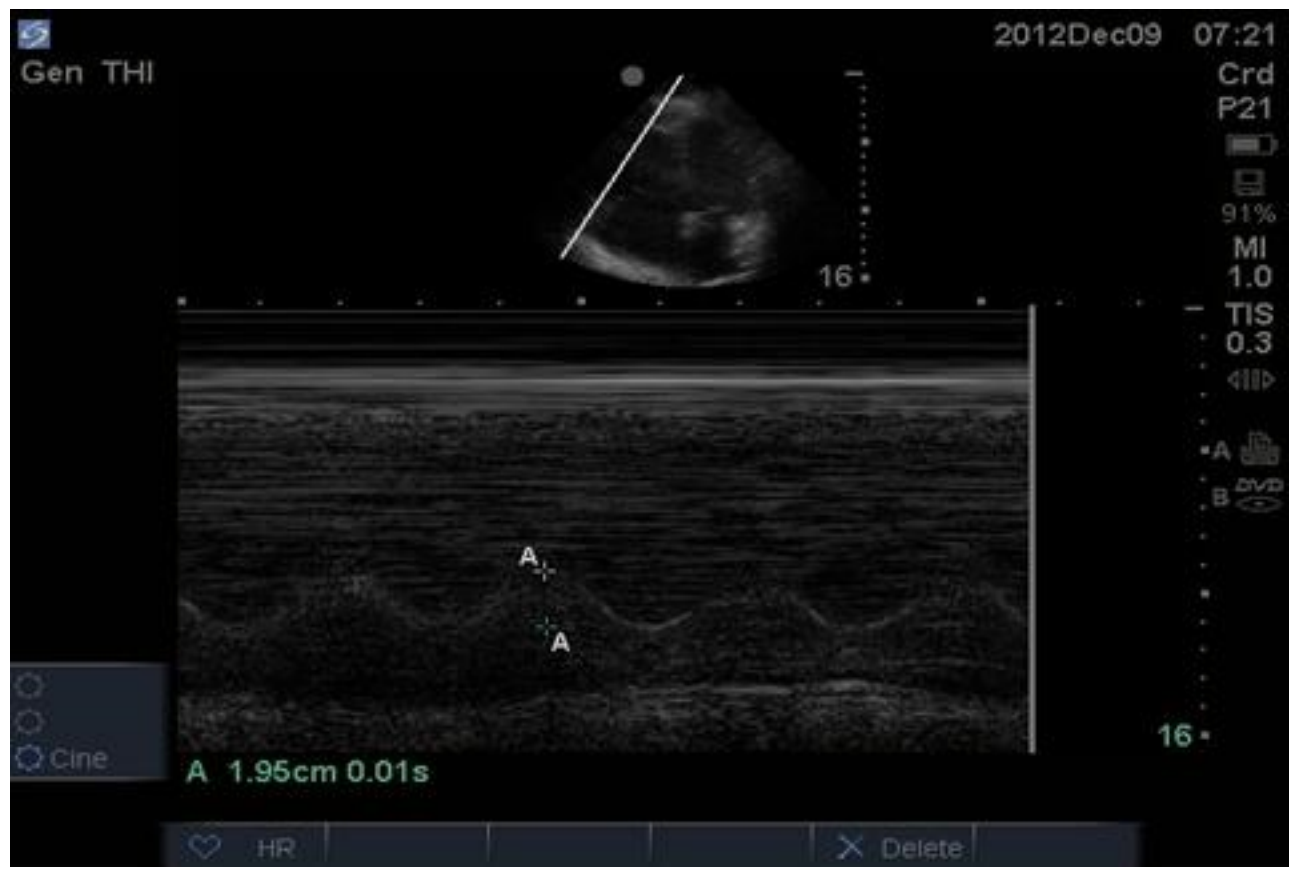

Figure 4. Tricuspid annular plane systolic excursion (TAPSE). M-mode through the lateral tricuspid annulus will demonstrate the amount of longitudinal excursion of the tricuspid annulus during systole. This has been shown to be a reliable indicator of right ventricular systolic function. 
Elevations in RV afterload or decreases in contractility are reflected by a lower TAPSE $(<16 \mathrm{~mm})(54,55)$. Septal movement is also used to demonstrate pressure or volume overload of the right ventricle. Obtained from a parasternal short axis view, septal flattening in systole represents pressure overload of the right ventricle whereas septal flattening in diastole represents volume overload (54). The presence of septal flattening along with a decreased TAPSE should alert the practioner to elevated pulmonary pressures and RV failure in the acutely hypotensive patient. Pulmonary artery systolic pressure can be calculated by continuous wave $(\mathrm{CW})$ Doppler of the tricuspid regurgitation jet obtained on an apical 4 chamber view $\left(p=4 \bigvee^{2}\right)(58)$. PA systolic pressure may be helpful to determine acute vs. chronic RV failure as the right ventricle is unable to overcome acute elevations in PA pressure $>40 \mathrm{mmHg}(54,59,60)$.

Case 3: A 56-year-old female presents by EMS with a seizure. She is found to be hypoxemic, unresponsive to supplemental oxygen, and hypotensive. She is given a fluid bolus immediately in the emergency department (ED), which worsens her hypotension and hypoxemia. The RECES protocol performed showed a dilated, hypodynamic right ventricle with a measured TAPSE of $12 \mathrm{~mm}$ (severely decreased). tPA was administered and repeat RECES exam demonstrated an improved TAPSE of $16 \mathrm{~mm}$ after 2 hours.

\section{Valves \\ Q: Is there obvious mitral, tricuspid, or aortic valve regurgitation? Yes or No}

No systematic study has been performed evaluating the ability of emergency or critical care physicians to diagnose valvular pathology with bedside ultrasound. A study done comparing handheld bedside sonography performed by cardiologists to standard echocardiography found good agreement between studies in diagnosing morphologic aortic and mitral valvular pathology (61). Literature describing clinician-performed bedside echocardiography to diagnose valvular disease is limited to case reports (62-64). Despite this, a grossly abnormal valve could be recognizable by bedside clinician sonographers. In scenarios of papillary muscle rupture or valvular vegetations, recognition of these conditions would dramatically influence care. A strong regurgitant jet across the aortic or mitral valve in the setting of shock should alert the physician to acute valvular incompetence or, in the right clinical setting, endocarditis with valvular deterioration.

\section{Limitations}

The RECES protocol is not without its limitations. First, there requires a training period to not only learn the mechanics of acquiring the ultrasound images, but also gaining the knowledge base to interpret the findings and manipulate hemodynamics based on those findings. The protocol attempts to simplify 
complex echocardiographic principles into simple questions, however still requires somewhat intricate knowledge of hemodynamic principles to interpret. Although ultrasound training has become a required component of emergency medicine training and enthusiasm is increasing in critical care training, there still remains a large proportion of physicians in both specialties with limited to no ultrasound skills and would be required to attend a national course to gain the prerequisite skill. Secondly, although echocardiography is immensely helpful in the critically ill, it can also be very difficult in some patients. Many patients are intubated and cannot cooperate with positioning, obese, or have chronic lung disease limiting the ability to acquire appropriate views.

\section{Conclusion}

This protocol does not intend to replace comprehensive echocardiography. The machine quality and level of training of bedside clinicians cannot match the level of expertise available with comprehensive echocardiography. However, there are many scenarios in which comprehensive echocardiography cannot be feasibly obtained for a critically ill patient. This protocol is intended to be rapidly performed and allow a treating physician to make immediate clinical decisions when circumstances do not allow for comprehensive echocardiography. Additionally, a limitation of comprehensive echocardiography in the early period of resuscitation is that the information obtained can quickly become obsolete in the setting of a dynamic situation of disease progression and aggressive resuscitation. However, a key component of this protocol is re-evaluation throughout the resuscitation to account for these rapid changes.

Our experience with this protocol shows that others with similar or adequate training in echocardiography can use this protocol to determine the volume responsiveness (IVCd, LVOT VTi) of their patient as well as presence of pericardial effusion with tamponade physiology (RV diastolic collapse, MV inflow variability), systolic failure (poor contractility, decreased SV and CO), diastolic dysfunction (MV inflow velocities and TDI), RV systolic failure (TAPSE), acute valvular rupture, obvious wall motion abnormalities, and signs of pressure or volume overload (septal flattening on parasternal short axis). Future studies should evaluate the learning curve for mastering the ultrasound skills necessary for reliably performing the RECES protocol.

\section{References}

1. Atkinson PR, McAuley DJ, Kendall RJ, et al. Abdominal and Cardiac Evaluation with Sonography in Shock (ACES): an approach by emergency physicians for the use of ultrasound in patients with undifferentiated hypotension. Emerg Med J. 2009;26(2):87-91. [CrossRef] [PubMed]

2. Jones AE, Tayal VS, Sullivan DM, Kline JA. Randomized, controlled trial of immediate versus delayed goal-directed ultrasound to identify the cause of 
nontraumatic hypotension in emergency department patients. Crit Care Med. 2004;32(8):1703-8.[CrossRef] [PubMed]

3. Perera P, Mailhot T, Riley D, Mandavia D. The RUSH exam: Rapid Ultrasound in SHock in the evaluation of the critically III. Emerg Med Clin North Am. 2010;28(1):29-56, vii. [CrossRef] [PubMed]

4. Rose JS, Bair AE, Mandavia D, Kinser DJ. The UHP ultrasound protocol: a novel ultrasound approach to the empiric evaluation of the undifferentiated hypotensive patient. Am J Emerg Med. 2001;19(4):299-302. [CrossRef] [PubMed]

5. Schmidt GA, Koenig S, Mayo PH. Shock: ultrasound to guide diagnosis and therapy. Chest. 2012;142(4):1042-8. [CrossRef] [PubMed]

6. Manno E, Navarra M, Faccio L, et al. Deep impact of ultrasound in the intensive care unit: the "ICU-sound" protocol. Anesthesiology. 2012;117(4):801-9. [CrossRef] [PubMed]

7. Emergency ultrasound guidelines. Ann Emerg Med. 2009;53(4):550-70. [CrossRef] [PubMed]

8. Labovitz AJ, Noble VE, Bierig M, et al. Focused cardiac ultrasound in the emergent setting: a consensus statement of the American Society of Echocardiography and American College of Emergency Physicians. J Am Soc Echocardiogr. 2010;23(12):1225-30. [CrossRef] [PubMed]

9. Gunst M, Sperry J, Ghaemmaghami V, O'Keeffe T, Friese R, Frankel H. Bedside echocardiographic assessment for trauma/critical care: the BEAT exam. J Am Coll Surg. 2008;207(3):e1-3. [CrossRef] [PubMed]

10. Mandavia DP, Hoffner RJ, Mahaney K, Henderson SO. Bedside echocardiography by emergency physicians. Ann Emerg Med. 2001;38(4):377-82. [CrossRef] [PubMed]

11. Schleder S, Dittmar M, Poschenrieder F, et al. Diagnosis of pericardial effusion with a new generation hand-carried ultrasound device in cardiothoracic intensive care unit patients. Acta Radiol. 2012;53(10):1133-6. [CrossRef] [PubMed]

12. Blaivas M. Incidence of pericardial effusion in patients presenting to the emergency department with unexplained dyspnea. Acad Emerg Med. 2001;8(12):1143-6. [CrossRef] [PubMed]

13. Nagdev A, Stone MB. Point-of-care ultrasound evaluation of pericardial effusions: does this patient have cardiac tamponade? Resuscitation. 2011;82(6):671-3. [CrossRef] [PubMed]

14. Goodman A, Perera P, Mailhot T, Mandavia D. The role of bedside ultrasound in the diagnosis of pericardial effusion and cardiac tamponade. J Emerg Trauma Shock. 2012;5(1):72-5. [CrossRef] [PubMed]

15. Hu K, Liu D, Niemann M, et al. Methods for assessment of left ventricular systolic function in technically difficult patients with poor imaging quality. J Am Soc Echocardiogr. 2013;26(2):105-13. [CrossRef] [PubMed]

16. Marwick TH. Techniques for comprehensive two dimensional echocardiographic assessment of left ventricular systolic function. Heart. 2003;89 Suppl 3:iii2-8. [CrossRef] [PubMed] 
17. Silverstein JR, Laffely NH, Rifkin RD. Quantitative estimation of left ventricular ejection fraction from mitral valve E-point to septal separation and comparison to magnetic resonance imaging. Am J Cardiol. 2006;97(1):137-40. [CrossRef] [PubMed]

18. Lehmann KG, Johnson AD, Goldberger AL. Mitral valve E point-septal separation as an index of left ventricular function with valvular heart disease. Chest. 1983;83(1):102-8. [CrossRef] [PubMed]

19. Ahmadpour H, Shah AA, Allen JW, Edmiston WA, Kim SJ, Haywood LJ. Mitral E point septal separation: a reliable index of left ventricular performance in coronary artery disease. Am Heart J. 1983;106(1 Pt 1):21-8. [CrossRef]

20. Secko MA, Lazar JM, Salciccioli LA, Stone MB. Can junior emergency physicians use E-point septal separation to accurately estimate left ventricular function in acutely dyspneic patients? Acad Emerg Med. 2011;18(11):1223-6. [CrossRef] [PubMed]

21. Weekes AJ, Reddy A, Lewis MR, Norton HJ. E-point septal separation compared to fractional shortening measurements of systolic function in emergency department patients: prospective randomized study. J Ultrasound Med. 2012;31(12):1891-7. [PubMed]

22. Weekes AJ, Tassone HM, Babcock A, et al. Comparison of serial qualitative and quantitative assessments of caval index and left ventricular systolic function during early fluid resuscitation of hypotensive emergency department patients. Acad Emerg Med. 2011;18(9):912-21. [CrossRef] [PubMed]

23. Randazzo MR, Snoey ER, Levitt MA, Binder K. Accuracy of emergency physician assessment of left ventricular ejection fraction and central venous pressure using echocardiography. Acad Emerg Med. 2003;10(9):973-7. [CrossRef] [PubMed]

24. Moore CL, Rose GA, Tayal VS, Sullivan DM, Arrowood JA, Kline JA. Determination of left ventricular function by emergency physician echocardiography of hypotensive patients. Acad Emerg Med. 2002;9(3):18693. [CrossRef] [PubMed]

25. Vincent JL, Sakr Y, Sprung CL, et al. Sepsis in European intensive care units: results of the SOAP study. Crit Care Med. 2006;34(2):344-53. [CrossRef] [PubMed]

26. Rosenberg AL, Dechert RE, Park PK, Bartlett RH. Review of a large clinical series: association of cumulative fluid balance on outcome in acute lung injury: a retrospective review of the ARDSnet tidal volume study cohort. J Intensive Care Med. 2009;24(1):35-46. [CrossRef] [PubMed]

27. Stewart RM, Park PK, Hunt JP, et al. Less is more: improved outcomes in surgical patients with conservative fluid administration and central venous catheter monitoring. J Am Coll Surg. 2009;208(5):725-35; discussion 735-37. [CrossRef] [PubMed]

28. Boyd JH, Forbes J, Nakada TA, Walley KR, Russell JA. Fluid resuscitation in septic shock: a positive fluid balance and elevated central venous pressure are associated with increased mortality. Crit Care Med. 2011;39(2):259-65. [CrossRef] [PubMed] 
29. Rivers E, Nguyen B, Havstad S, et al. Early goal-directed therapy in the treatment of severe sepsis and septic shock. N Engl J Med. 2001;345(19):1368-77. [CrossRef] [PubMed]

30. Kumar A, Anel R, Bunnell E, et al. Pulmonary artery occlusion pressure and central venous pressure fail to predict ventricular filling volume, cardiac performance, or the response to volume infusion in normal subjects. Crit Care Med. 2004;32(3):691-9. [CrossRef] [PubMed]

31. Osman D, Ridel C, Ray $\mathrm{P}$, et al. Cardiac filling pressures are not appropriate to predict hemodynamic response to volume challenge. Crit Care Med. 2007;35(1):64-8. [CrossRef] [PubMed]

32. Marik PE, Baram M, Vahid B. Does central venous pressure predict fluid responsiveness? A systematic review of the literature and the tale of seven mares. Chest. 2008;134(1):172-8. [CrossRef] [PubMed]

33. Berkenstadt $\mathrm{H}$, Margalit $\mathrm{N}$, Hadani $\mathrm{M}$, et al. Stroke volume variation as a predictor of fluid responsiveness in patients undergoing brain surgery. Anesth Analg. 2001;92(4):984-9. [CrossRef] [PubMed]

34. Barbier C, Loubieres Y, Schmit C, et al. Respiratory changes in inferior vena cava diameter are helpful in predicting fluid responsiveness in ventilated septic patients. Intensive Care Med. 2004;30(9):1740-6. [CrossRef] [PubMed]

35. Feissel M, Michard F, Faller JP, Teboul JL. The respiratory variation in inferior vena cava diameter as a guide to fluid therapy. Intensive Care Med. 2004;30(9):1834-7. [CrossRef] [PubMed]

36. Kramer A, Zygun D, Hawes H, Easton P, Ferland A. Pulse pressure variation predicts fluid responsiveness following coronary artery bypass surgery. Chest. 2004;126(5):1563-8. [CrossRef] [PubMed]

37. Michard F, Lopes MR, Auler JO, Jr. Pulse pressure variation: beyond the fluid management of patients with shock. Crit Care. 2007;11(3):131. [CrossRef] [PubMed]

38. Cannesson M. Arterial pressure variation and goal-directed fluid therapy. J Cardiothorac Vasc Anesth. 2010;24(3):487-497. [CrossRefl [PubMed]

39. Moretti R, Pizzi B. Inferior vena cava distensibility as a predictor of fluid responsiveness in patients with subarachnoid hemorrhage. Neurocritical Care. 2010;13(1):3-9. [CrossRef] [PubMed]

40. Maguire S, Rinehart J, Vakharia S, Cannesson M. Technical communication: respiratory variation in pulse pressure and plethysmographic waveforms: intraoperative applicability in a North American academic center. Anesth Analg. 2011;112(1):94-6. [CrossRef] [PubMed]

41. Michard F, Teboul JL. Using heart-lung interactions to assess fluid responsiveness during mechanical ventilation. Crit Care. 2000;4(5):282-289. [CrossRef] [PubMed]

42. Michard $\mathrm{F}$, Boussat $\mathrm{S}$, Chemla $\mathrm{D}$, et al. Relation between respiratory changes in arterial pulse pressure and fluid responsiveness in septic patients with acute circulatory failure. Am J Respir Crit Care Med. 2000;162(1):134-8. [CrossRef] [PubMed] 
43. Scheuren K, Wente MN, Hainer C, et al. Left ventricular end-diastolic area is a measure of cardiac preload in patients with early septic shock. Eur J Anaesthesiol. 2009;26(9):759-65. [CrossRef] [PubMed]

44. Vincent JL. Intensive Care Medicine: Annual Update 2008. 1 ed: Springer; 2008.

45. Levitov A, Marik PE. Echocardiographic assessment of preload responsiveness in critically ill patients. Cardiol Res Prac. 2012;2012:819696. [CrossRef] [PubMed]

46. Slama M, Masson $\mathrm{H}$, Teboul JL, et al. Respiratory variations of aortic VTI: a new index of hypovolemia and fluid responsiveness. Am J Physiol Heart Circ Physiol. 2002;283(4):H1729-1733. [PubMed]

47. Lewis JF, Kuo LC, Nelson JG, Limacher MC, Quinones MA. Pulsed Doppler echocardiographic determination of stroke volume and cardiac output: clinical validation of two new methods using the apical window. Circulation. 1984;70(3):425-31. [CrossRef] [PubMed]

48. Dinh VA, Ko HS, Rao R, et al. Measuring cardiac index with a focused cardiac ultrasound examination in the ED. Am J Emerg Med. 2012;30(9):1845-51. [CrossRef] [PubMed]

49. Cannesson M, Tran NP, Cho M, Hatib F, Michard F. Predicting fluid responsiveness with stroke volume variation despite multiple extrasystoles. Crit Care Med. 2012;40(1):193-8. [CrossRef] [PubMed]

50. Nagueh SF, Appleton CP, Gillebert TC, et al. Recommendations for the evaluation of left ventricular diastolic function by echocardiography. J Am Soc Echocardiogr. 2009;22(2):107-33. [CrossRef] [PubMed]

51. Ommen SR, Nishimura RA. A clinical approach to the assessment of left ventricular diastolic function by Doppler echocardiography: update 2003. Heart. 2003;89 Suppl 3:iii18-23. [CrossRef] [PubMed]

52. Unluer EE, Bayata S, Postaci N, et al. Limited bedside echocardiography by emergency physicians for diagnosis of diastolic heart failure. Emerg Med J. 2012;29(4):280-3. [CrossRef] [PubMed]

53. Kerwin C, Tommaso L, Kulstad E. A brief training module improves recognition of echocardiographic wall-motion abnormalities by emergency medicine physicians. Emerg Med Int. 2011;2011:483242. [CrossRef] [PubMed]

54. Haddad F, Hunt SA, Rosenthal DN, Murphy DJ. Right ventricular function in cardiovascular disease, part I: Anatomy, physiology, aging, and functional assessment of the right ventricle. Circulation. 2008;117(11):1436-48. [CrossRef] [PubMed]

55. Rudski LG, Lai WW, Afilalo J, et al. Guidelines for the echocardiographic assessment of the right heart in adults: a report from the American Society of Echocardiography. J Am Soc Echocardiogr. 2010;23(7):685-713; quiz 786-8. [CrossRef] [PubMed]

56. Doutreleau S, Talha S, Di Marco P, Lebourg F, Rouyer O, Geny B. Does tricuspid annular plane systolic excursion (TAPSE) or systolic velocity (Sm) allow an easier determination of right ventricular function after heart 
transplantation? J Heart Lung Transplant. 2007;26(3):302-303. [CrossRef]

[PubMed]

57. Tousignant C, Kim H, Papa F, Mazer CD. Evaluation of TAPSE as a measure of right ventricular ouptut. Can J Anaesth. 2012;59(4):376-383. [CrossRef] [PubMed]

58. Piazza G, Goldhaber SZ. The acutely decompensated right ventricle: pathways for diagnosis and management. Chest. 2005;128(3):1836-52. [CrossRef] [PubMed]

59. Haddad F, Doyle R, Murphy DJ, Hunt SA. Right ventricular function in cardiovascular disease, part II: pathophysiology, clinical importance, and management of right ventricular failure. Circulation. 2008;117(13):1717-31. [CrossRef] [PubMed]

60. Chin KM, Kim NH, Rubin LJ. The right ventricle in pulmonary hypertension. Coronary artery disease. 2005;16(1):13-8. [CrossRef] [PubMed]

61. Giusca S, Jurcut R, Ticulescu R, et al. Accuracy of handheld echocardiography for bedside diagnostic evaluation in a tertiary cardiology center: comparison with standard echocardiography. Echocardiography. 2011;28(2):136-41. [CrossRef] [PubMed]

62. Riley DC, Cordi HP. Emergency department diagnosis of mitral stenosis and left atrial thrombus using bedside ultrasonography. Acad Emerg Med. 2010;17(5):e30-1. [CrossRef] [PubMed]

63. Sautner J, Budhram G. Diagnosis of acute mitral valve insufficiency using emergency bedside echocardiography. Acad Emerg Med. 2009;16(7):685-6. [CrossRef] [PubMed]

64. Seif D, Meeks A, Mailhot T, Perera P. Emergency department diagnosis of infective endocarditis using bedside emergency ultrasound. Crit Ultrasound $\mathrm{J}$. 2013;5(1):1. [CrossRef] [PubMed]

Corresponding Author:

Jarrod M. Mosier, MD

Assistant Professor

Department of Emergency Medicine

Department of Medicine, Section of Pulmonary, Critical Care, Allergy and

Sleep

University of Arizona

1609 N Warren

FOB $122 \mathrm{C}$

Tucson, Az 85719

Phone: $775-527-1292$

Fax: 520-626-2480

imosier@aemrc.arizona.edu

Disclosures: None for any authors 